\title{
Accuracy of Soluble Endoglin for Diagnosis of Preeclampsia and its Severity
}

\author{
Pooneh Nikuei ${ }^{1}$, Minoo Rajaei ${ }^{* 2}$, Kianoosh Malekzadeh ${ }^{* 1,3}$, Azim \\ Nejatizadeh $^{1,3}$, Fatemeh Mohseni $^{1}$ and Ali AtashAbParvar ${ }^{4}$
}

\begin{abstract}
${ }^{1}$ Molecular Medicine Research Center, Hormozgan Health Institute, Hormozgan University of Medical Sciences, Bandar Abbas, Iran; ${ }^{2}$ Fertility and Infertility Research Center, Hormozgan University of Medical Sciences, Bandar Abbas, Iran; ${ }^{3}$ Department of Medical Genetics; Faculty of Medicine; Hormozgan University of Medical Sciences, Bandar Abbas, Iran; ${ }^{4}$ Pathology Department, Faculty of Medicine, Hormozgan University of Medical Sciences, Bandar Abbas, Iran
\end{abstract}

Received 11 January 2017; revised 15 January 2017; accepted 19 January 2017

\begin{abstract}
Background: The use of biomarkers for diagnosis of Preeclampsia (PE), a life-threatening pregnancy disorder, could reduce serious complications of this disease. In this study, we investigated dysregulation of endoglin (Eng) expression and diagnostic accuracy of soluble endoglin (sEng) in PE patients. Methods: For this case-control study, 26 mild and 15 severe preeclamptic women along with 20 normotensive controls were recruited. The expression level of Eng (the co-receptor of TGF- $\beta 1$ ) was evaluated using qRT-PCR. Also, the serum concentration of soluble Eng and expression of membranous Eng were determined by ELISA and immunohistochemistry. Results: $A$ significant up-regulation in Eng mRNA and sEng levels was observed in PE patients versus normal controls. Immunohistochemistry (IHC) showed up-regulation of membranous Eng staining in syncytiotrophoblast and cytotrophoblast cells of PE patients. The serum levels of sEng were significantly increased in all patients (mild, sever, early- and late-onset) as compared to healthy pregnant women $(P<0.001)$. Receiver-operating characteristic (ROC) curve analysis revealed that sEng had the highest accuracy in distinguishing PE from normal pregnancies with cut-off value of 20.4 , sensitivity of $92.1 \%$, specificity of $90 \%$, and area under the curve (AUC) of 0.94 (95\% Cl: 0.88-1.00). Conclusions: Our data showed that the up-regulation of Eng mRNA along with its membranous and soluble form in PE patients leads to defect in angiogenesis pathway. Also, the results of this study revealed sEng potential as a marker for diagnosis of PE and its severity. DOI: 10.18869/acadpub.ibj.21.5.312
\end{abstract}

Keywords: Preeclampsia, Endoglin, Biomarkers, Pregnancy

*Corresponding Authors: Minoo Rajaei and Kianoosh Malekzadeh

Fertility and Infertility Research Center, Shariati Hospital, Hormozgan University of Medical Sciences, Bandar Abbas, Iran; Tel./Fax: (+98-76) 33354939; Mobile: (+98-917) 1617034; E-mail: Minoo.Rajaei@hums.ac.ir

Molecular Medicine Research Center (MMRC); Shahid Mohammadi Hospital; Hormozgan University of Medical Sciences (HUMS), Bandar Abbas, Iran; Tel./Fax: (+98-76) 33354939; Mobile: (+98-917) 6108396; E-mail: kianoosh.malekzadeh@HUMS.ac.ir

\section{INTRODUCTION}

$\mathrm{P}$ reeclampsia (PE) is one of the most critical complications of pregnancy and characterized by hypertension and proteinuria after 20 weeks of gestation $^{11}$. It affects $5-8 \%$ of all pregnancies and is responsible for 60,000 maternal deaths and more fetal and neonatal deaths every year ${ }^{[2]}$. PE imposes a considerable expenses on patients and healthcare system $^{[3]}$. In order to reduce serious complications of $\mathrm{PE}$ and early treatment interventions, initial diagnosis of high risk women for developing PE is important. Biomarkers for prediction of PE before manifestation of clinical symptoms in early pregnancy would help to identify such cases for more careful follow-up and early interventions ${ }^{[4]}$. Currently, there is no definite 
treatment for PE, except preterm delivery of placenta and fetus, which increases the risk of disability and death of the newborn, especially in severe early-onset cases $^{[5]}$.

Despite uncertain etiology of PE, angiogenesis defect in the early stages of pregnancy results in incomplete remodeling of uterine spiral arterioles, abnormal placental vascular development, and endothelial dysfunction as the main causes of $\mathrm{PE}^{[6-8]}$. Various studies have indicated the role of soluble endoglin (sEng), an anti-angiogenic factor, in the etiology of $\mathrm{PE}^{[1,9]}$.

Eng or CD105 is a homodimeric transmembrane glycoprotein that is localized on cell surfaces and acts as a co-receptor for transforming growth factor (TGF)$\beta 1$ and TGF- $\beta 3$ isoforms ${ }^{[10]}$. Eng is known to have a main function in vascular tone maintenance via the regulation of nitric oxide dependent vasodilatation, and probably control placental implantation and spiral artery remodeling during pregnancy ${ }^{[11]}$. Involvement of Eng in PE has already been studied based on its role in systemic endothelial dysfunction, shallow placental implantation, and spiral artery remodeling demonstrated as principal pathophysiologic abnormalities in this disease ${ }^{[11]}$. This study was designed to evaluate the expression alterations of Eng as well as to assess the usefulness of sEng as a diagnostic biomarker for PE patients.

\section{MATERIALS AND METHODS}

\section{Patients and sampling}

A total of 61 pregnant women, 41 preeclamptic cases and 20 normotensive controls, were recruited for this case-control study. All participants were selected from two hospitals in Bandar Abbas and were provided written informed consent for serum and placental tissue collection under the protocols approved by the Ethical Committee of Hormozgan University of Medical Sciences (No. 1-HEC-93-7-8) from 2014 to 2015. Participants did not receive any medication before sampling. Preeclamptic women were divided into mild $(n=26)$ and severe $(n=15)$, and cases were subdivided in 9 early- and 32 late-onset PE, respectively.

PE definition was determined based on the American Congress of Obstetricians and Gynecologists guidelines as: gestational hypertension (systolic pressure $>140 \mathrm{mmHg}$ or diastolic blood pressure $>90$ $\mathrm{mmHg}$ on two or more occasions after gestational week 20) with proteinuria ( $>0.3 \mathrm{~g} /$ day). Severe PE was defined if more than one of the following criteria were present: (i) severe gestational hypertension (systolic pressure $>160 \mathrm{~mm} \mathrm{Hg}$ or diastolic blood pressure $>110$ $\mathrm{mm} \mathrm{Hg}$ on two or more occasions after gestational week 20), (ii) severe proteinuria ( $\geq 5 \mathrm{~g}$ of protein in a 24-h urine specimen), (iii) oliguria $<500 \mathrm{ml}$ in $24 \mathrm{~h}$, (iv) cerebral or visual disturbances, (v) pulmonary edema or cyanosis, (vi) epigastric or right upperquadrant pain, (vii) impaired liver function, (viii) thrombocytopenia or (ix) fetal growth restriction ${ }^{[12]}$. Early-onset PE was considered as $(<34+0$ weeks $)$ and late-onset $\mathrm{PE}$ as $(\geq 34+0 \text { weeks })^{[13]}$.

Women with diabetes, collagen vascular diseases, renal disease, chronic or gestational hypertension, and fetal anomalies were excluded from the study. Immediately after delivery and after removal of chorionic plate and overlaying fetal membranes, small pieces of tissues biopsies $\left(2 \mathrm{~cm}^{3}\right.$ each) were randomly obtained from about $2 \mathrm{~cm}$ beside the umbilical cord insertion and from areas without infarction and hemorrhage. Placental tissues were washed in sterile PBS and placed in tubes containing RNAlater solution (Qiagen, Germany) and stored at $-80^{\circ} \mathrm{C}$ until RNA extraction. Placenta samples of 15 women $(5$ mild, 5 severe, and 5 normal) were immersion-fixed in $10 \%$ formalin and after that embedded in paraffin wax. The whole blood samples were centrifuged at $3000 \times \mathrm{g}$ for $20 \mathrm{~min}$, and the separated serum samples were stored at $-80^{\circ} \mathrm{C}$ for ELISA.

\section{RNA extraction}

Total RNA was extracted from placental samples (approximately $100 \mathrm{mg}$ ) using TRIZOL reagent (Sigma-Aldrich, USA). The extracted RNA was then treated with RNase-free DNase-I (Thermo Scientific, USA) according to the manufacturer's instructions. The quality and quantity of the extracted RNA were evaluated by agarose gel electrophoresis and spectrophotometery (NanoDrop ND-1000, Thermo Scientific, USA), respectively.

\section{cDNA synthesize and quantitative real-time PCR (qRT-PCR)}

Total RNA $(2 \mu \mathrm{g})$ was reverse transcribed to cDNA by the RevertAid ${ }^{\mathrm{TM}}$ First Strand cDNA Synthesis Kit (Fermentas, Canada) using random hexamer primer following the manufacturer's protocol. qRT-PCR was conducted by a real-time PCR system (Corbett, RotorGene 6000, Australia) using specific primer sets for each gene (Table 1) and Syber Green-Master Mix (Takara Syber Premix Ex Taq, Japan) according to the manufacturer's instructions. All reactions were set as 20- $\mu \mathrm{l}$ mixture containing $2 \mu \mathrm{l}$ cDNA, $10 \mu \mathrm{l}$ Master Mix $2 \times, 0.4 \mu \mathrm{l}$ ROX dye $50 \times$ and $10 \mathrm{pmol}$ of each primer pair for Eng, TGF- $\beta 1$, and $\beta$-actin (1.6 $\mu 1)$. The thermal cycling status was initial denaturation at $95^{\circ} \mathrm{C}$ for $30 \mathrm{~s}$, followed by 40 cycles of denaturation at $94^{\circ} \mathrm{C}$ 
Table 1. Primer sequences, amplicon sizes, and the annealing temperature in quantitative real-time PCR

\begin{tabular}{llcc}
\hline Gene & Sequence of primers $\mathbf{5}^{\prime} \rightarrow \mathbf{3}^{\prime}$ & Size & An. Temp. \\
$(\mathbf{b p})$ & 149 & 62 \\
\hline \multirow{2}{*}{ Th- $\beta 1$} & F: CGACTACTACGCCAAGGAGGT' & & \\
& R: AGAGCAACACGGGTTCAGGTA & & 62 \\
Endoglin & F: AGGCGGTGGTCAATATCC & 109 & 58 \\
$\beta$-actin & R: AAGTGTGGGCTGAGGTAG & & 50 \\
\hline
\end{tabular}

An.Temp., annealing temperature; $\mathrm{F}$, forward primer; $\mathrm{R}$, reverse primer

for $5 \mathrm{~s}$, annealing at temperatures for each primer pair for $15 \mathrm{~s}$, extension at $60^{\circ} \mathrm{C}$ for $30 \mathrm{~s}$. The expression levels of TGF- $\beta 1$ and Eng were normalized by $\beta$-actin expression as house-keeping gene and calculated by the $2^{-\Delta \Delta \mathrm{CT}}$ method

\section{ELISA}

ELISA was performed on 58 serum samples including 23 mild PE patients, 15 severe PE patients, and 20 normal pregnancies. In case group, 9 women were affected with early-onset PE, and 29 women suffered from late-onset PE. Serum Eng level was determined by using a commercially available Quantikine Human Eng Immunoassay kit (R\&D Systems, USA) according to the procedure provided by the manufacturer.

\section{Immunohistochemistry}

IHC for Eng was performed on placental tissues obtained from preeclamptic and healthy pregnant women. Briefly, paraffin sections, which were mounted on glass slides, dewaxed in xylene and rehydrated using descending grade of ethanol (100, 96, and 70). Tissue sections were heated for 5 minutes at a $1000-\mathrm{W}$ microwave then 15 minutes at $300-\mathrm{W}$ and cooled at room temperature for 20 minutes. The sections were washed in PBS ( $\mathrm{pH} 7.6)$ for 10 minutes and immersed in $\mathrm{H}_{2} \mathrm{O}_{2} 3 \%$ solved in methanol at room temperature for 10 minutes. The sections were then washed with $\mathrm{PBS}$ and incubated at $4-6^{\circ} \mathrm{C}$ overnight with 1:150 diluted primary rabbit polyclonal antibody Eng (H-300: sc-20632, Santa Cruz, USA). Afterwards, the sections were washed with PBS and ChemMate $^{\mathrm{TM}}$ DAKO EnVision ${ }^{\mathrm{TM}}$ Detection Kit, peroxidase/3,3'-diaminobenzidine (DAB), rabbit/ mouse (DakoCytomation, Denmark) was applied according to manufacturer's instructions following staining with hematoxylin (DDK, Italia). For negative controls, primary antibody was deleted and for positive controls human kidney tissue was used. All slides were processed at the same time and were examined under a microscope (Olympus CX31RBSF, Japan).

\section{Statistical analysis}

One-way ANOVA/Kruskal-Wallis test with Bonferroni correction was used for comparing the data between multiple groups and Mann-Whitney test/unpaired $t$-test for comparison between two groups based on Kolmogorov-Smirnov test for normality distribution. Data were shown as number (\%) and mean $( \pm \mathrm{SD})$. qRT-PCR data were analyzed by GraphPad prism software (version 5.0; GraphPad Software Inc., San Diego, CA). Dunnet's post hoc test was used to compare the expression level between the groups. $P<0.05$ was considered statistically significant. The receiver-operating characteristic (ROC) curve analysis was carried out to show the cut-off serum levels of sEng in PE patients compared to normal pregnancies using statistical software STATA 11 (Texas, USA).

\section{RESULTS}

There was no significant difference in maternal age $(P=0.816)$ between case and control groups. Clinical characteristics are displayed in Table 2.

\section{Up-regulation of endoglin expression in preeclampsia patients}

The result of mRNA expression showed no significant difference for TGF- $\beta 1$ in PE patients compared with controls. Eng expression in mRNA level was significantly up-regulated in all groups of the patients compared to the controls, which was more significant in severe and early-onset PE patients (mild PE $(P<0.05)$, severe PE $(P<0.01)$, early-onset $(P<0.01)$ late-onset $(P<0.05)$. The altered expression of TGF- $\beta 1$ and its co-receptor Eng in PE are displayed in Figure 1.

\section{Increased serum level of soluble endoglin in Preeclampsia patients}

The mean serum level of sEng in women with mild $\mathrm{PE}$ was $24.08 \pm 3.05 \mathrm{ng} / \mathrm{mL}$ and in severe $\mathrm{PE}$ was $26.34 \pm 3.37 \mathrm{ng} / \mathrm{mL}$ as compared with $13.58 \pm 5.80$ $\mathrm{ng} / \mathrm{mL}$ in healthy controls. Preeclamptic women 
Table 2. Clinical characteristics of the women participated in the study

\begin{tabular}{lccc}
\hline Parameter & PE $(\mathbf{n}=\mathbf{4 1})$ & Controls $(\mathbf{n}=\mathbf{2 0})$ & $\boldsymbol{P}$ value \\
\hline Mental age (year) & $27.20 \pm 5.66$ & $26.85 \pm 4.84$ & 0.816 \\
Placental weight $(\mathrm{g})$ & $427 \pm 85.04$ & $609 \pm 49.41$ & $<0.001$ \\
BMI before pregnancy & $23.82 \pm 3.88$ & $23.31 \pm 3.49$ & 0.385 \\
SBP (mmHg) & $15.61 \pm 1.58$ & $11.38 \pm 0.67$ & 0.001 \\
DBP (mm Hg) & $10.04 \pm 0.92$ & $6.90 \pm 0.72$ & 0.001 \\
Parity & & & \\
$\quad$ Primiparous & $19(46.3 \%)$ & $9(45 \%)$ & 0.921 \\
$\quad$ Multiparous & $22(53.7 \%)$ & $11(55 \%)$ & \\
Previous PE & $6(14.6 \%)$ & 0 & 0.165 \\
\hline
\end{tabular}

Results are presented as mean \pm SD. BMI, body mass index; SBP, systolic blood pressure; DBP, diastolic blood pressure; n, number; PE, preeclampsia
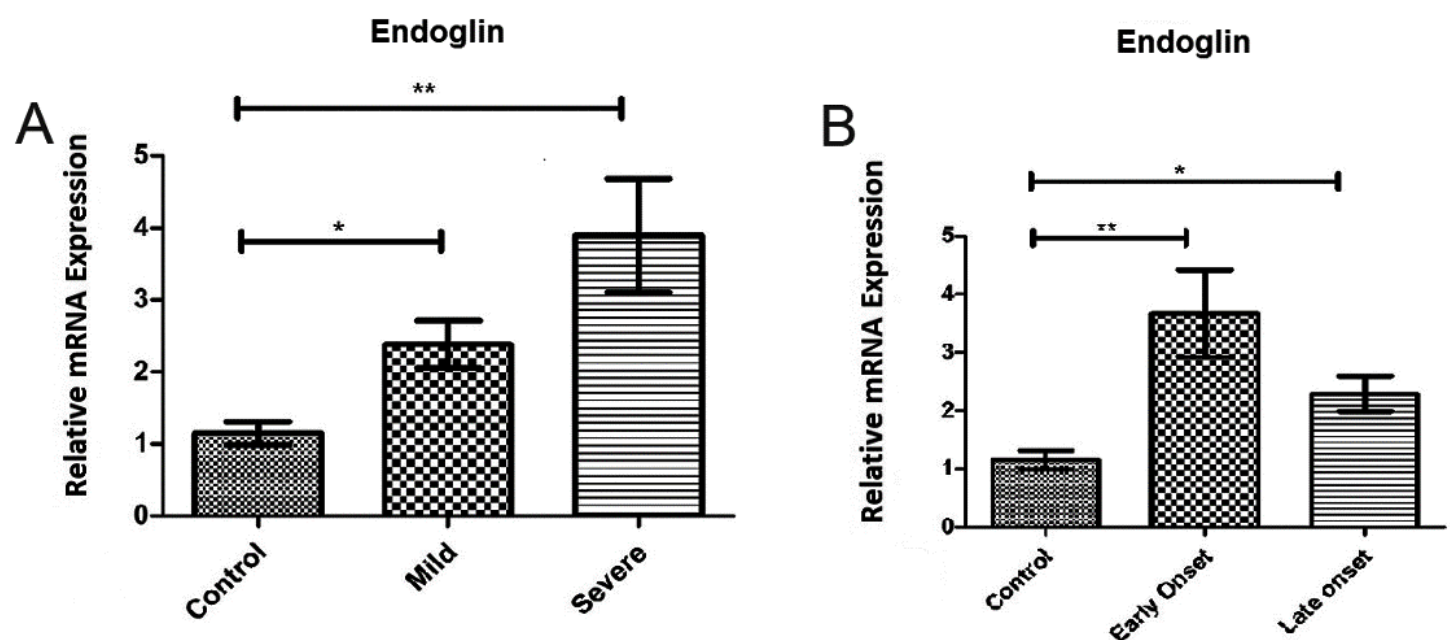

TGFB 1

TGFB1
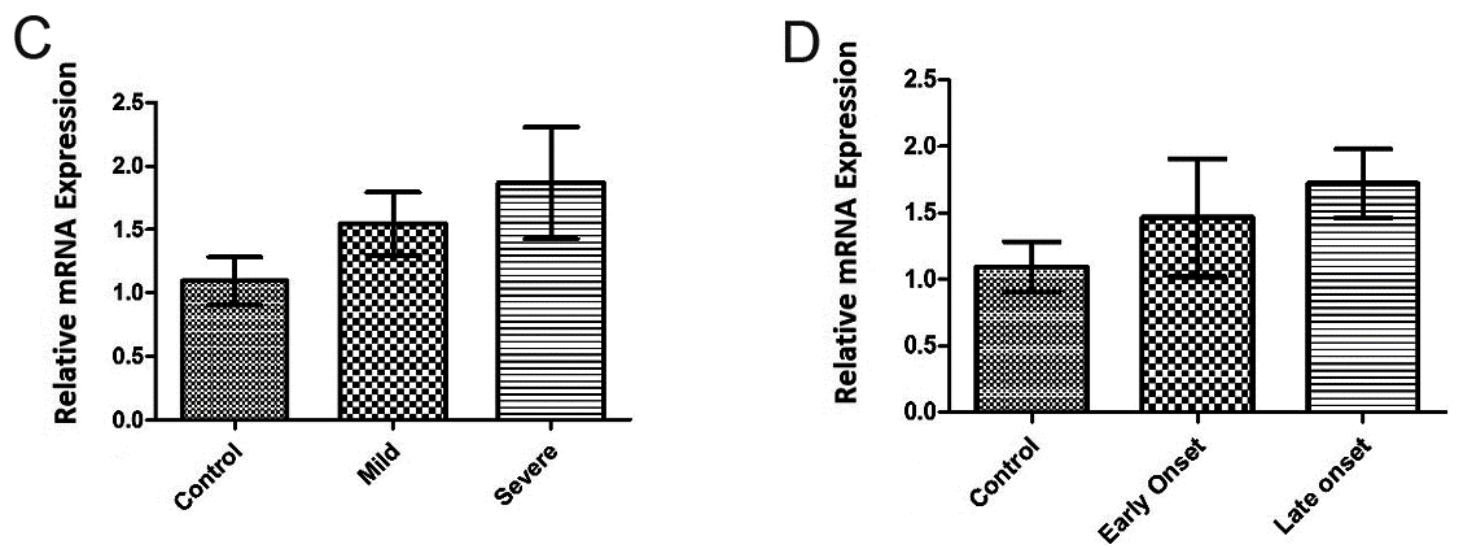

Fig. 1. Placental expression of endoglin (Eng) and TGF- $\beta 1$ mRNA in preeclampsia (PE) compared to uncomplicated term pregnancy. Eng mRNA expression among patients with mild and severe (A) as well as early- and late-onset PE (B) showed a significant up-regulation in all groups of patients in comparison with controls. TGF- $\beta 1 \mathrm{mRNA}$ expression among patients with mild and severe (C) and also early- and late-onset PE (D) indicated no significant difference in comparison with controls. Values are presented as mean \pm S.E.M. ${ }^{*} P<0.05,{ }^{* *} P<0.01$, respectively. 

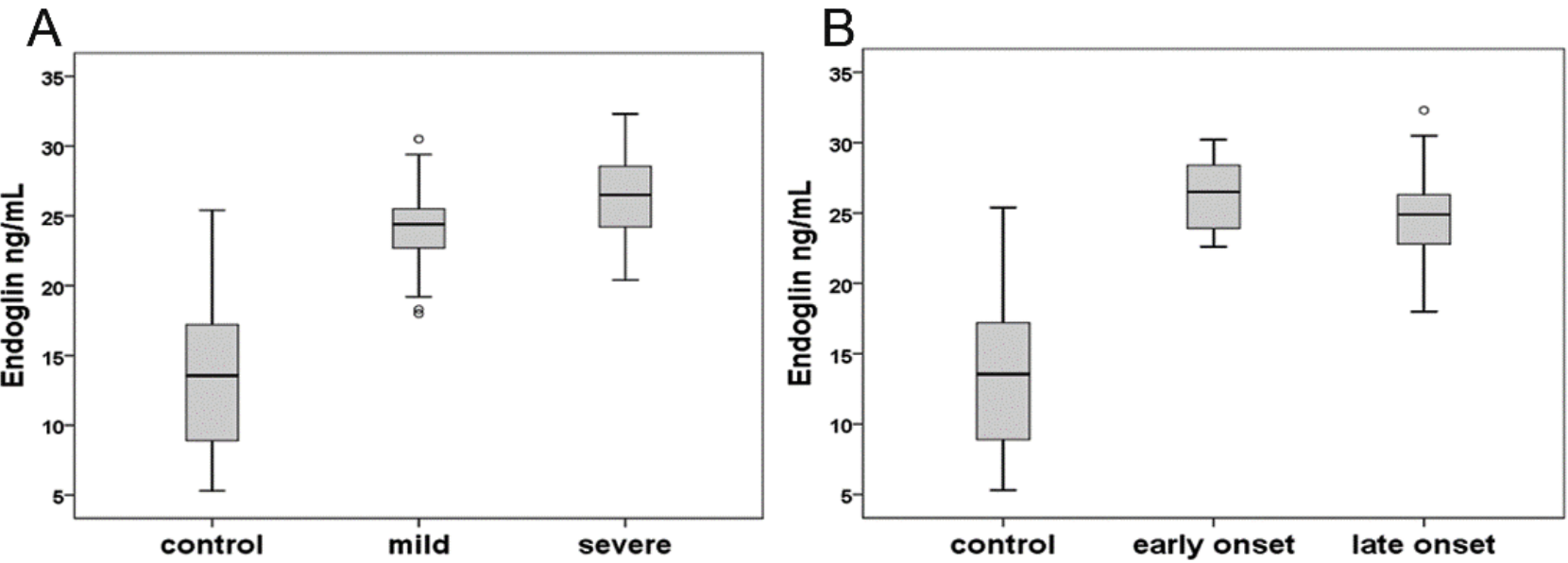

Fig. 2. Levels of soluble Endoglin (sEng) in preeclampsia (PE) patients and controls. Comparison of sEng level between mild and sever PE patients with controls (A); early- and late-onset PE patients with controls (B) shows a significant increase in all PE groups in comparison with normal women. The $10^{\text {th }}$ and $90^{\text {th }}$ centiles are represented by lower and upper bars, and horizontal lines in the box show median. The circles represent outliers.

showed increased levels of sEng in both mild and severe groups compared to the control group $(P<0.001)$. Also, a significant increase $(P<0.001)$ was observed in the serum level of sEng in early-onset (26.10 \pm 2.68$)$ and late-onset PE patients $(24.62 \pm 3.47)$ in comparison with the control group (Fig. 2). In addition, there was no significant difference between mild and severe groups as well as the early- and lateonset groups ( $P=0.349$ and $P=1.0$, respectively).

\section{Receiver-operating characteristic curve analysis}

The results of ROC curve analysis showed the highest diagnostic accuracy for sEng in diagnosis of preeclamptic patients from normal women with AUC of 0.94 (95\% CI: 0.88-1.00), sensitivity and specificity of $92.1 \%$ and $90.0 \%$, respectively. sEng had less accuracy in the detection of severe and early-onset PE patients (Fig. 3 and Table 3).

\section{Staining of endoglin in syncytiotrophoblast and cytotrophoblast cells of preeclampsia patients}

Immunohistochemistry analysis showed severe intensity of staining which was observed predominantly in syncytiotrophoblast and cytotrophoblast cells of severe PE patients and moderate intensity in placenta of mild PE patients. Eng was localized in placenta of controls with mild intensity of staining (Fig. 4 and Table 4).

\section{DISCUSSION}

Defect in angiogenesis, trophoblastic invasion, and uterine spiral artery remodeling are key events in the etiology of PE. Since TGF- $\beta 1$ and its co-receptor, Eng, are involved in angiogenesis; therefore this hypothesis can be raised that alterations in expression of these genes have role in PE, and perhaps soluble form of Eng can be considered as a diagnostic biomarker for the identification of PE patients. According to our knowledge, this is the first study that investigates the TGF- $\beta 1$ expression as well as soluble and membranous Eng expression in PE, particularly in placental tissue among Iranian population.

Our study did not show any significant changes in mRNA expression level of TGF- $\beta 1$ in placental tissue of severe, mild, early- and late-onset PE, compared to healthy controls. However, there was only one study regarding TGF- $\beta 1$ mRNA expression in placenta tissue of women affected with PE that reported an increased

Table 3. The performance of serum endoglin in diagnosis of preeclampsia (PE)

\begin{tabular}{lcccccccc}
\hline Groups & cut off & Sn & Sp & LR+ & LR- & PPV & NPV & Area (95\% CI) \\
\hline PE & $\geq 20.4$ & 92.1 & 90 & $\mathbf{9 . 2}$ & 0.08 & 94.6 & 85.7 & $0.94(0.88-1.00)$ \\
Sever PE & $\geq 24$ & 80 & 65 & 2.2 & 0.30 & 44.4 & 90.3 & $0.82(0.71-0.94)$ \\
Early-onset PE & $\geq 24.4$ & 66.6 & 63.2 & 1.8 & 0.52 & 25 & 91 & $0.76(0.61-0.90)$ \\
\hline
\end{tabular}

Sn, sensitivity; Sp, specificity; LR, likelihood Ratio; PPV, positive predictive value; NPV, negative predictive value; CI, confidence interval 

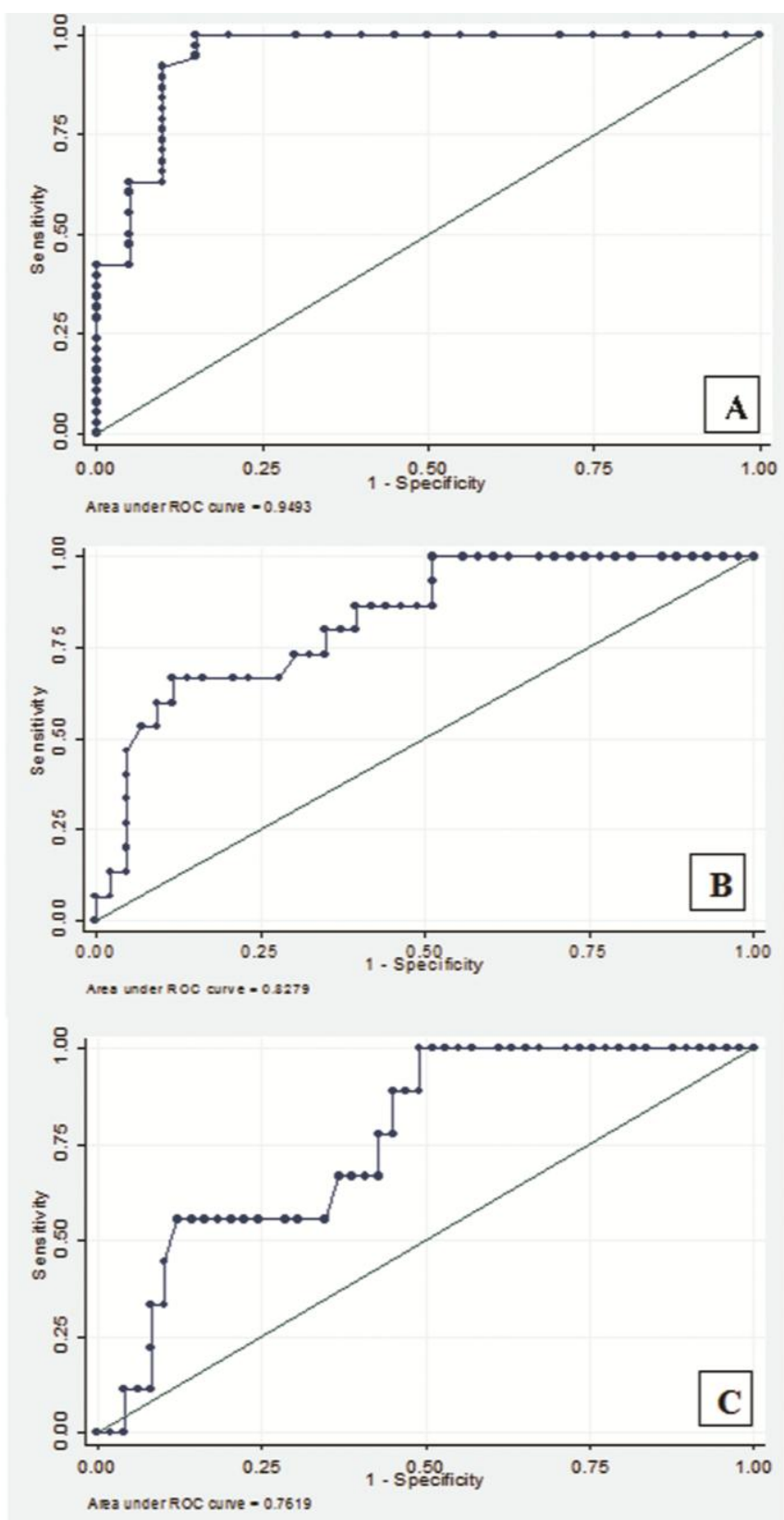

Fig. 3. Performance of serum soluble endoglin (sEng) in diagnosis of preeclampsia (PE). Receiver-operating characteristic curve analysis of sEng levels in PE shows the ability of maternal serum sEng to differentiate: PE from normal pregnancies (A), severe PE patients (B), and early-onset PE patients (C).

TGF- $\beta 1$ mRNA expression in chorionic villous samples from pregnant women who suffered from PE later in the pregnancy ${ }^{[14]}$.

Our data confirmed significant up-regulation of Eng mRNA in all patients, particularly with severe and early-onset of PE. These results are in accordance with the findings of other studies that reported up-regulation of Eng mRNA in $\mathrm{PE}^{[15-17]}$. Serum level of sEng was also evaluated, and a significant increase of sEng serum levels was found in all PE patients versus controls, while early-onset and severe PE patients had the highest sEng level. The results obtained for sEng level in PE are in line with those of numerous studies regarding this marker ${ }^{[1,9,18]}$.

Angiogenesis defect in the early stages of pregnancy results in incomplete remodeling of spiral arterioles of uterus and abnormal placental vascular development as the main pathological finding in $\mathrm{PE}^{[8]}$. Eng is expressed in vascular endothelial cells, synctyiotrophoblasts, and invasive cytotrophoblasts and involved in placental 
Table 4. The membranous protein expression detected by immunohistochemistry in placenta tissue

\begin{tabular}{lcccc}
\hline Groups & Cytotrophoblast & Syncytiotrophoblast & Endothelial & Hofbauer \\
\hline Control & + & + & - & - \\
Mild & ++ & ++ & + & + \\
Severe & +++ & +++ & ++ & + \\
\hline
\end{tabular}

$(+)$, staining in more than $10 \%$ of cells with mild intensity; (++): moderate staining; (+++), severe staining. $(-)$ is $<10 \%$ intensity of staining

implantation and spiral arterioles remodeling ${ }^{[1,19,20]}$. Eng regulates TGF- $\beta 1$ signaling pathway by interacting with TGF- $\beta 1$ receptor I and II, and also as a pro-angiogenic factor regulates nitric oxide-dependent vasodilation $^{[21]}$. Overproduction of anti-angiogenic peptides like sEng is a response to placental ischemia, which is due to inadequate trophoblast invasion and contributes to the inhibition of angiogenesis ${ }^{[9,22]}$. Actually, sEng binds to TGF- $\beta 1$ and prevents the attachment of TGF- $\beta 1$ to its cell membrane receptors and inhibits the regulation of trophoblasts invasion ${ }^{[21]}$. The data of this study indicated that Eng mRNA and protein expression were increased in trophoblast cells (cytotrophoblasts and synctyiotrophoblasts) in PE patients. This phenomenon can be explained as a compensatory response of placenta to hypoxia. Also, results revealed that sEng was increased in the serum of PE women, which might be a potential diagnostic

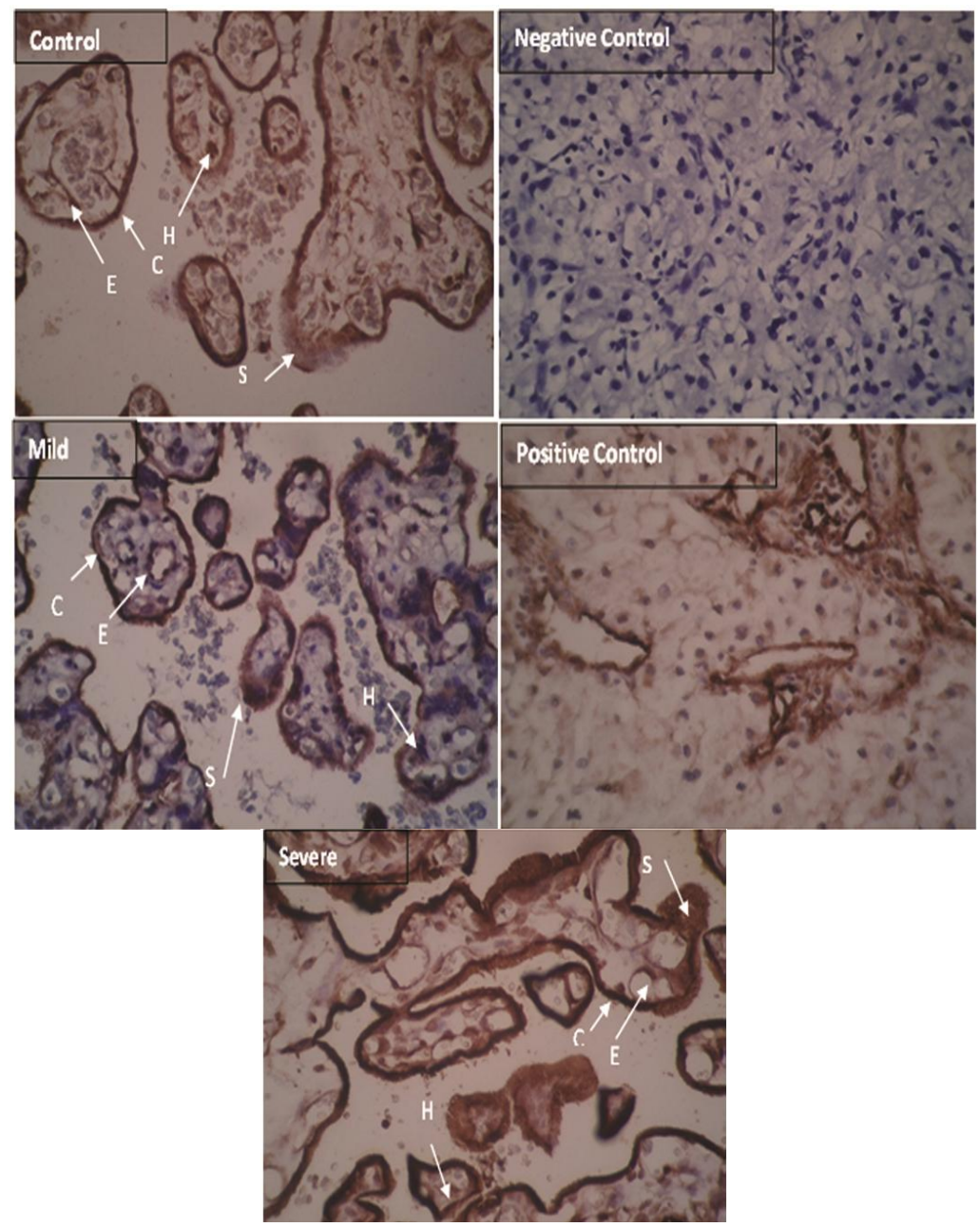

Fig. 4. Immunohistochemistry of endoglin (Eng) in preeclampsia (PE) and control placenta. Eng is localized predominantly in syncytiotrophoblast and cytotrophoblast cells in PE patients. S, syncytiotrophoblast; C, cytotrophoblast; E, endothelial cells; H, Hofbauer cells (scale bar: $20 \mu \mathrm{m}$ ). Arrows show trophoblast cells. 
marker for $\mathrm{PE}$ in addition to blood pressure and proteinuria. AUC of 0.95 with more than $90 \%$ sensitivity and specificity refers to high accuracy of serum sEng in diagnosis of PE from normal pregnant women. Calculated positive and negative likelihood ratio and also positive and negative predictive value suggest sEng ability in this regard. Although sEng, based on our results, can be considered as a marker with high accuracy in identification of PE, this serum marker has lower accuracy for detecting severe and early-onset PE patients due to its lower sensitivity and specificity in the mentioned situations. De Vivo et $a l .{ }^{[23]}$ have studied on serum samples between 24 and 28 weeks of gestation and showed the usefulness of sEng in early prediction of PE with more than $80 \%$ sensitivity and specificity. Lim et al. ${ }^{[18]}$ have reported AUC of 0.83 for sEng in predicting PE. Baumann et $a l .{ }^{[24]}$, reported AUC of 0.62 for sEng in predicting $\mathrm{PE}$ in first trimester serum in women with subsequent lateonset PE. Based on our ROC curve analysis, sEng has remarkable accuracy for diagnosis of PE from normal pregnant women compared with its ability for identification of severe and early-onset cases. Our main limitation was loss to follow-up patients from early pregnancy stages, before the onset of PE, and only patients diagnosed with PE were involved in our study as the case group. Therefore, evaluation of sEng, as a candidate marker, in a larger sample size and follow-up of patients from the earlier stages of pregnancy are suggested for longitudinal studies.

The present study showed the up-regulation of both membranous and soluble form of Eng in trophoblast cells of PE patients. Also, our data showed the usefulness of sEng, as a potential marker with high accuracy for diagnosis of PE and its severity. Prospective longitudinal studies in different populations are suggested to elucidate sEng as a diagnostic biomarker in PE patients.

\section{ACKNOWLEDGEMENTS}

This work was financially supported by Research Vice-Chancellor of Hormozgan University for Medical Science (HUMS) (grant number: 9379).

CONFLICT OF INTEREST. None declared.

\section{REFERENCES}

1. Levine RJ, Lam C, Qian C, Yu KF, Maynard SE, Sachs BP, Sibai BM, Epstein FH, Romero R, Thadhani R, Karumanchi SA; CPEP Study Group. Soluble endoglin and other circulating antiangiogenic factors in preeclampsia. The New England journal of medicine 2006; 355(10): 992-1005.

2. Brownfoot F, Hannan N, Onda K, Tong S4, Kaitu'uLino T. Soluble endoglin production is upregulated by oxysterols but not quenched by pravastatin in primary placental and endothelial cells. Placenta 2014; 35(9): 724-731

3. Rana S, Powe CE, Salahuddin S, Verlohren S, Perschel FH, Levine RJ, Lim KH, Wenger JB, Thadhani R, Karumanchi SA. Angiogenic factors and the risk of adverse outcomes in women with suspected preeclampsia. Circulation 2012; 125(7): 911-919.

4. Wu P, van den Berg C, Alfirevic Z, O'Brien S, Röthlisberger M, Baker PN, Kenny LC, Kublickiene K, Duvekot JJ. Early pregnancy biomarkers in preeclampsia: a systematic review and meta-analysis. International journal of molecular sciences 2015; 16(9): 23035-23056.

5. Kaitu'u-Lino T, Hastie R, Cannon P, Nguyen H, Lee S, Hannan NJ, Tong S. Transcription factors E2F1 and E2F3 are Kaitu'u expressed in placenta but do not regulate MMP14. Placenta 2015; 36(8): 932-937.

6. Kar, M. Role of biomarkers in early detection of preeclampsia. Journal of clinical and diagnostic research 2014; 8(4): BE01- BE04.

7. Wang Y, Wang Q, Guo C, Wang S, Wang X, An L, Cao X, Qiu Y, Wang G, Li H, Ma X. Association between $\mathrm{CRP}$ gene polymorphisms and the risk of preeclampsia in Han Chinese women. Genetic testing and molecular biomarkers 2014; 18(11): 775-780.

8. Wolf M, Hubel CA, Lam C, Sampson M, Ecker JL, Ness RB, Rajakumar A, Daftary A, Shakir AS, Seely EW, Roberts JM, Sukhatme VP, Karumanchi SA, Thadhani R. Preeclampsia and future cardiovascular disease: potential role of altered angiogenesis and insulin resistance. The journal of clinical endocrinology and metabolism 2004; 89(12): 6239-6243.

9. Aggarwal P, Chandel N, Jain V, Jha V. The relationship between circulating endothelin-1, soluble fms-like tyrosine kinase- 1 and soluble endoglin in preeclampsia. Journal of human hypertension 2010; 26(4): 236-241.

10. Perucci LO, Gomes KB, Freitas LG, Godoi LC, Alpoim PN, Pinheiro MB, Miranda AS, Teixeira AL, LM Dusse, Sousa LP. Soluble endoglin, transforming growth factor-Beta 1 and soluble tumor necrosis factor alpha receptors in different clinical manifestations of preeclampsia. PloS one 2014; 9(5): e97632.

11. Bell MJ, Roberts JM, Founds SA, Jeyabalan A, Terhorst L, Conley YP. Variation in endoglin pathway genes is associated with preeclampsia: a case-control candidate gene association study. BMC pregnancy and childbirth 2013; 13(1): 82.

12. American College of Obstetricians and Gynecologsts: ACOG practice bulletin 33: diagnosis and management of preeclampsia and eclampsia. Obstetrics and Gynecology 2002; 99: 159-167.

13. Von Dadelszen P, Magee LA, Roberts JM. Subclassification of preeclampsia. Hypertension in pregnancy 2003; 22(2): 143-148. 
14. Farina A, Sekizawa A, De Sanctis P, Purwosunu Y, Okai T, Cha DH, Kang JH, Vicenzi C, Tempesta A, Wibowo N, Valvassori L, Rizzo N. Gene expression in chorionic villous samples at 11 weeks' gestation from women destined to develop preeclampsia. Prenatal diagnosis 2008; 28(10): 956-961.

15. Purwosunu Y, Sekizawa A, Yoshimura S, Farina A, Wibowo N, Nakamura M, Shimizu H, Okai T. Expression of angiogenesis-related genes in the cellular component of the blood of preeclamptic women. Reproductive sciences 2009; 16(9): 857-864.

16. Sekizawa A, Purwosunu Y, Farina A, Shimizu H, Nakamura M, Wibowo N, Rizzo N, Okai T. Prediction of pre-eclampsia by an analysis of placenta-derived cellular mRNA in the blood of pregnant women at 1520 weeks of gestation. BJOG 2010; 117(5): 557-564.

17. Sitras V, Paulssen RH, Grønaas H, Leirvik J, Hanssen TA, Vårtun A, Acharya G. Differential placental gene expression in severe preeclampsia. Placenta 2009; 30(5): 424-433.

18. Lim JH, Kim SY, Park SY, Yang JH, Kim MY, Ryu HM. Effective prediction of preeclampsia by a combined ratio of angiogenesis-related factors. Obstetrics and gynecology 2008; 111(6): 1403-1409.

19. Caniggia I, Taylor CV, Ritchie JW, Lye SJ, Letarte M. Endoglin regulates trophoblast differentiation along the invasive pathway in human placental villous explants. Endocrinology 1997; 138(11): 4977-4988.
20. Toporsian M, Gros R, Kabir MG, Vera S, Govindaraju K, Eidelman DH, Husain M, Letarte M. A role for endoglin in coupling eNOS activity and regulating vascular tone revealed in hereditary hemorrhagic telangiectasia. Circulation research 2005; 96(6): 684692.

21. Lim JH, Kim SY, Park SY, Lee HM, Yang JH, Kim MY, Chung JH, Lee SW, Ryu HM. Soluble endoglin and transforming growth factor- $\beta 1$ in women who subsequently developed preeclampsia. Prenatal diagnosis 2009; 29(5): 471-476.

22. Hawinkels LJ, Kuiper P, Wiercinska E, Verspaget HW, Liu Z, Pardali E, Sier CF, ten Dijke P. Matrix metalloproteinase-14 (MT1-MMP)-mediated endoglin shedding inhibits tumor angiogenesis. Cancer research 2010; 70(10): 4141-4150.

23. De Vivo A, Baviera G, Giordano D, Todarello G, Corrado F, D'anna R. Endoglin, PIGF and sFlt-1 as markers for predicting pre-eclampsia. Acta obstetricia et gynecologica scandinavica 2008; 87(8): 837-842.

24. Baumann MU, Bersinger NA, Mohaupt MG, Raio L, Gerber S, Surbek DV. Firs-trimester serum levels of soluble endoglin and soluble fms-like tyrosine kinase-1 ats first-trimester markers for late-onset preeclampsia. American journal of obstetrics and gynecology 2008; 199(3): 266. e1-e6. 